\title{
Comparative Assessment and Multivariate Optimization of Commercially Available Small Scale Reverse Osmosis Membranes
}

\author{
M. C. $\operatorname{Garg}^{1 *}$ and H. Joshi ${ }^{2}$ \\ ${ }^{1}$ Amity Institute of Environmental Sciences (AIES), Amity University Uttar Pradesh, Sector-125, Noida, Uttar Pradesh 201313, India \\ ${ }^{2}$ Department of Hydrology, Indian Institute of Technology Roorkee, Roorkee, Uttrakhand 247667, India
}

Received 18 March 2014; revised 9 July 2015; accepted 21 September 2015; published online 27 February 2017

\begin{abstract}
Requirement of reverse osmosis (RO) process at places facing energy and water quality problem makes its assessment and optimization vital while considering recovery, rejection as well as specific energy consumption. In the present paper, three thin film composite (TFC) RO membranes (make: CSM, Dow and Vontron) in spiral wound (SW) configuration have been chosen to study their relative performance. Comparative study of RO membranes was conducted using experimental observations supported by membrane characterization. Optimization experiments were performed using central composite design (CCD) of response surface methodology (RSM). Four input variables viz. feed water $\mathrm{pH}$, temperature, pressure and concentration were optimized and interaction between them was observed, while, recovery, rejection and specific energy consumption (SEC) were taken as response attributes. The experiments conducted employing the optimized input values validated the developed RSM model. Predictive model using multiple response optimization revealed the optimal efficiency of CSM RO membrane at $6.53 \mathrm{pH}, 1500 \mathrm{mg} / \mathrm{L}$ concentration, $0.78 \mathrm{MPa}$ pressure and $31.94^{\circ} \mathrm{C}$ temperature producing $19.25 \%$ water recovery, $89.21 \%$ salt rejection and $17.60 \mathrm{kWh} / \mathrm{m}^{3} \mathrm{SEC}$, respectively. Membrane surface characterization was carried out by FE-SEM, AFM, contact angle measurement and FTIR. The lesser contact angle and smoother surface apparently contributed to the better performance of CSM RO membrane. This paper may demonstrate a simple method for optimizing the commercially available small scale RO membranes.
\end{abstract}

Keywords: brackish groundwater treatment, multivariate optimization, RSM, small scale reverse osmosis membranes, specific energy consumption

\section{Introduction}

Freshwater problems implying degrading groundwater quality and increasing treatment costs are expected to increase in coming years. The degradation in groundwater quality (geogenic and anthropogenic) at the source level is mainly due to the intensification of agriculture along with non-judicious use of fertilizers and pescticides, addition of solid and liquid wastes and their residuals resulting from rapid urbanization and widespread reduction in recharge of severely strained aquifers to meet ever rising water demands (Champidi et al., 2011). Poor groundwater quality has many economic costs associated with it, one of which is towards the water treatment. Desalination has meanwhile emerged as a solution for locations, where access to water is limited and groundwater has become increasingly saline (UNEP, 2012). Small reverse osmosis (RO) desalination units, mostly installed by the private sector, can now be found as a secondary source of drinking water where municipal supplies are not delivered (World Bank, 2009). Mo-

${ }^{*}$ Corresponding author. Tel.: +91 9760295790; fax: +91 1204392406.

E-mail address: manoj28280@gmail.com (M. C. Garg).

ISSN: $1726-2135$ print/1684-8799 online

(C) 2017 ISEIS All rights reserved. doi: 10.3808/jei.201700357 reover, RO process has been continuously improved for producing drinking water from brackish groundwater and seawater all over the world (Elsaid and Abdel-Wahab, 2012). Commercially available small scale RO process can remove dissolved ions and therefore is well suited for brackish groundwater treatment (Hamouda et al., 2013).

As a higher feed water recovery would result in smaller installation size of the membrane unit as well as have less capital and operating costs, few studies concerning the evaluation and optimization of small scale RO membranes (sufficient for 10 to 25 people in a community) have been carried out that mainly focussed on maximizing water recovery and salt rejection (Elfil et al., 2007; Khayet et al., 2011; Hamouda et al., 2013). In addition, environmental problem and energy crisis in near future will be more obvious due to increasing demand of fossil fuel (Şen, 2004), therefore, the expectation for development of energy conserving RO systems, while maximizing recovery and rejection are more prominent. Application of the small scale RO plants at the areas facing energy challenges such as military operations, catastrophic calamities and natural disasters may be possible. So far, multivariate optimization, characterization and comparison of the comercially available small scale RO systems have not been given much attention and thereby need to be studied. The main objec- 
tives of this work are performance evaluation of the comercially available small scale RO system with an aim to increase water recovery, salt rejection and at the same time to minimize the SEC.

Present paper deals with the optimization and characterization of three commercially available RO membranes used in small scale community level systems in India. Therefore, optimization experiments were carried out to maximize water recovery and salt rejection along with the minimization of energy consumption of small scale brackish water RO process using $\mathrm{pH}$, feed temperature, feed pressure and concentration of feed solution as input parameters. Synthetic water nearly close to actual groundwater was used for all the experiments. Due to the considerable contribution of response surface methodology (RSM) in improving precision and accuracy of estimated optimized values of process variables, it is usually employed for experiment design (Razali et al., 2013). The advantages of RSM include reduction in number of experiments and minimization of experimental cost and time consumption (Ferreira et al., 2007a; Zhao et al., 2014). In the present study, optimization was performed employing RSM using centre composite design (CCD). Furthermore, validation experiment of these membrane results was also conducted as per the obtained optimized value of RSM prediction. Characterization of membranes was carried out by atomic force microscopy (AFM), scanning electron microscopy (FE-SEM), fourier transform infrared spectroscopy (FTIR) and contact angle measurement. A correlation between surface properties and membrane filtration results was obtained.

\section{Methods}

\subsection{Artificial Groundwater Formulation}

To evaluate the present groundwater quality situation in India, Delhi region was selected for our study. Groundwater sample was collected from Timarpur, Delhi (India). Analysis of various drinking water quality parameters reveals that the feed water of the RO plant was contaminated in terms of dissolved component comprising primarily of calcium $(\mathrm{Ca})$, magnesium $(\mathrm{Mg})$, chloride $(\mathrm{Cl})$ and sulphate $\left(\mathrm{SO}_{4}\right)$ necessitating Thus, the use of RO treatment plant for this type of water.

As the laboratory scale RO membrane experiments are generally not practically feasible with actual brackish groundwater due to its inadequate availability and fluctuating quality (Bohdziewicz et al., 1999; Mehdizadeh, 2006; Rahardianto et al., 2007), hence, in the present study, synthetic water was formulated in the laboratory on the basis of major ionic elements of actual groundwater and was further used for performing different experiments. For the formation of synthetic water, a mathematical matrix based computation was employed for estimation of the desired composition of different constituents (Adams and Bubucis, 1998). Based on this formulation, synthetic water was prepared in the laboratory by using analytical grade chemicals (make: Merck, India). Furthermore, to validate the accuracy of this formulation, concentration of elements of the synthetic water were analysed experimentally an- d compared with that of actual groundwater.

Experimental results of the constituent concentrations of the synthetic groundwater came very close to those (correlation coefficient 0.9982 ) in actual ground water. This synthetic water was used further in different optimization experiments.

\subsection{Experimental Setup and Operational Procedure}

A laboratory scale RO membrane system (Make: Permionics membrane Pvt. Ltd., Vadodara, Gujrat, India) was installed to investigate the performance of various spiral wound RO membranes. Figure 1 shows a schematic diagram of the laboratory scale RO system. It consists of a feed water tank, high pressure pump, membrane module consisting of spiral wound RO membrane having $5 \mathrm{~cm}$ diameter and $30.5 \mathrm{~cm}$ length. Synthetic ground water was used as feed water in all the experiments. The concentration of feed water was in the range of $500-4,500 \mathrm{mg} / \mathrm{L}$.

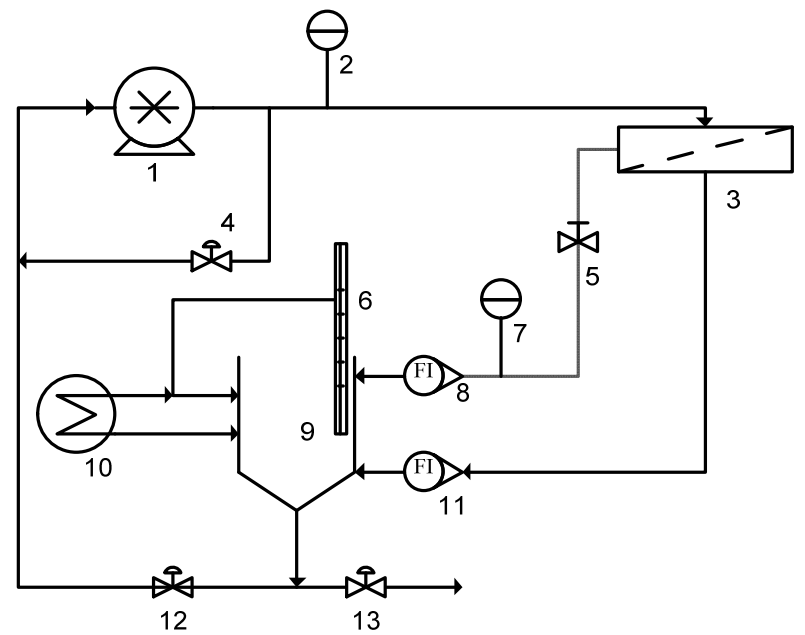

Note: $1=$ high pressure pump, $2=$ feed pressure gauge, $3=\mathrm{RO}$ module, $4=$ bypass valve, $5=$ pressure control valve, $6=$ temperature probe, $7=$ concentrate pressure gauge, $8=$ concentrate flow meter, $9=$ feed water tank, $10=$ temperature controller, $11=$ permeate flow meter, $12 \& 13=$ valve.

Figure 1. Experimental scheme of laboratory level small scale RO desalination plant.

Feed flow rate was kept constant during experiments by pumping feed water along a feed bypass valve. The system pressure was adjusted using a concentrate valve and monitored by a pressure gauge. Minimum and maximum pressure applied in RO experiments were within the prescribed limits recommended by membrane manufacturers (Table 1). The feed water was pumped to the RO membrane which rejected the dissolved ions from feed water and allowed fresh water to permeate through it.

The concentrate and permeate streams were recycled into the feed water tank for continuous evaluation of the system. After every run, the system was thoroughly rinsed with Milli$\mathrm{Q}$ water for several minutes and completely drained after- 
wards. Feed water temperature was kept constant by automatic temperature controlling unit using circulating hot/cold water. $15 \mathrm{~mL}$ water samples were collected simultaneously every hour from the feed and permeate. The temperature, $\mathrm{pH}$ and electrical conductivity of each of these samples, in addition to the permeate flow rate (from which flux was calculateed), were measured.

Optimization experiments were carried out to maximize water recovery, salt rejection and to minimize SEC of small scale brackish water RO process (Joyce et al., 2001) for given feed water $\mathrm{pH}$, temperature, pressure and concentration.

The concentration of anions and cations in samples was estimated using the Ion Chromatograph (Make: Metrohm Ltd., Switzerland). Conductivity meter (Sension, HACH) was used to determine the TDS of feed and permeate water. The salt rejection (\%) was calculated using following equation (Mane et al., 2009):

Salt rejection $(\%)=\left(1-\frac{C_{p}}{C_{f}}\right) \times 100$

where $C_{f}=$ feed concentration in $\mathrm{mg} / \mathrm{L}$, and $C_{p}=$ product water concentration $(\mathrm{mg} / \mathrm{L})$. The feed water recovery $(\%)$ of was calculated by using following equation (Koutsou et al., 2015):

Water recovery $(\%)=\left(\frac{Q_{p}}{Q_{f}}\right) \times 100$

where $Q_{p}=$ permeate flow rate $(\mathrm{L} / \mathrm{h})$, and $Q_{f}=$ feed flow rate $(\mathrm{L} / \mathrm{h})$. Also, SEC was calculated from the following equa- tion (Zhu et al., 2009):

$S E C=\left(\frac{I \times V}{Q_{p}}\right) k W h / m^{3}$

where SEC is the specific energy consumption in $\mathrm{kWh} / \mathrm{m}^{3}, I=$ current intensity $(A)$, and $V=$ electrical potential $(V)$ of $\mathrm{AC}$ power used to operate the motor.

\subsection{Membranes}

Three Thin film composite (TFC) RO membranes from three leading manufacturing companies (CSM, Dow and Vontron) in spiral wound configuration were used to perform laboratory scale experiments. Operating specifications of these membranes were used for limiting the range of input parameters for each membrane (Table 1). The membranes were preconditioned by soaking in DI water for 2 days, followed by thorough rinsing using DI water prior to testing.
Table 1. Range of Input Variables Taken in Different RO Membranes Experiments

\begin{tabular}{lllllll}
\hline \multirow{2}{*}{ Actual input variables } & Coded & \multicolumn{2}{l}{ Coded level } & & \\
\cline { 3 - 7 } & symbol & $-\alpha$ & -1 & 0 & +1 & $+\alpha$ \\
\hline CSM & & & & & & \\
\hline Temperature $\left({ }^{\circ} \mathrm{C}\right)$ & $\mathrm{A}$ & 20 & 24 & 28 & 32 & 36 \\
Pressure $(\mathrm{MPa})$ & $\mathrm{B}$ & 0.49 & 0.59 & 0.69 & 0.78 & 0.88 \\
Concentration $(\mathrm{mg} / \mathrm{L})$ & $\mathrm{C}$ & 500 & 1500 & 2500 & 3500 & 4500 \\
$\mathrm{pH}$ & $\mathrm{D}$ & 5 & 6 & 7 & 8 & 9 \\
\hline Dow & & & & & & \\
\hline Temperature $\left({ }^{\circ} \mathrm{C}\right)$ & $\mathrm{A}$ & 20 & 24 & 28 & 32 & 36 \\
Pressure $(\mathrm{MPa})$ & $\mathrm{B}$ & 0.59 & 0.88 & 1.18 & 1.47 & 1.77 \\
Concentration $(\mathrm{mg} / \mathrm{L})$ & $\mathrm{C}$ & 500 & 1500 & 2500 & 3500 & 4500 \\
pH & $\mathrm{D}$ & 5 & 6 & 7 & 8 & 9 \\
\hline Vontron & & & & & & \\
\hline Temperature $\left({ }^{\circ} \mathrm{C}\right)$ & $\mathrm{A}$ & 15 & 20 & 25 & 30 & 35 \\
Pressure $(\mathrm{MPa})$ & $\mathrm{B}$ & 0.29 & 0.59 & 0.88 & 1.18 & 1.47 \\
Concentration $(\mathrm{mg} / \mathrm{L})$ & $\mathrm{C}$ & 500 & 1500 & 2500 & 3500 & 4500 \\
pH & $\mathrm{D}$ & 5 & 6 & 7 & 8 & 9 \\
\hline
\end{tabular}

\subsection{Experimental Design}

To reduce the number of experiments and to minimize the experimental cost and time, RSM is generally employed ( $\mathrm{Ra}-$ zali et al., 2013).

To determine both linear and quadratic models, CCD based statistical experimental design was used (Idris et al., 2006; Khayet et al., 2011a; Razali et al., 2013; Chakraborty et al., 2014). It combines two level full factorial (cubic) designs (Qi$\mathrm{n}$ et al., 2008) with additional axial (star) points and a set of centre points at the centre of the experimental region (Wang et al., 2013a). The centre points were repeated to improve the precision of experiments (Bezerra et al., 2008; Ferreira et al., $2007 b)$. During RS modelling, input variables $\left(x_{1}, x_{2}, \ldots, x_{n}\right)$ in coded scale level vary from the minimum level (-1) up to the maximum level $(+1)$. To determine a critical point (maximum, minimum, or saddle), a second-order model containing quadratic terms is often used and can be presented in a general form as:

$y=\beta_{0}+\sum_{i=1}^{n} \beta_{i} x_{i}+\sum_{i=1}^{n} \beta_{i i} x_{i}^{2}+\sum_{i<j}^{n} \beta_{i j} x_{i} x_{j}+\varepsilon$

where $y$ denotes the predicted response, $x_{i}$ refers to the coded levels of input variables; $\beta_{0}, \beta_{i}, \beta_{i i}$ and $\beta_{i j}$ are the regression coefficients (constant term, linear, quadratic and interaction parameters); $n$ is the number of variables and $\varepsilon$ is the experimental error, which is assumed to be random with zero mean (Bezerra et al., 2008; Wang et al., 2013b). In RSM model solution, homogeneity was assumed for all factors that were continuously monitored and regulated (Shuman, 1995). Design Expert software (Stat-Ease Inc., version 7) was used for graphical analysis and model fitting. 
In this study, the mutual effect and the relative significance of four input factors on the performance of RO membrane process was investigated by employing RSM with CCD (Khayet et al., 2011b). Experiments were carried out for different ranges of concentration, temperature, $\mathrm{pH}$ and pressure of feed water (Table 1). A total of 30 experiments were proposed by the design expert software, comprising 16 factorial experiments, 8 axial experiments and 6 replicative experiments at the central point as highlighted in the following equation:

$N=2^{n}+2 n+n_{c}=2^{4}+(2 \times 4)+6=30$

where $N$ is the total number of experiments required, $n$ is the number of numeric factors and $n_{c}$ is replicate number at the central point. Further, multi-parameter non-linear regression models were developed as actual and coded factors (Montgomery, 2004).

Actual and coded values of input variables used in RSM are given in Table 1. RS model was solved for maximizing the water recovery and salt rejection while minimizing SEC. Three dimensional surface plots for response surfaces (RS) were generated from the developed model. Validation experiments were conducted employing the optimal values of the input parameters to verify the predicted values of the RSM.

\subsection{Membrane Characterization}

Characterization of different RO membranes was carried out by AFM, FE-SEM, FTIR and contact angle measurement. All RO membrane samples were extensively rinsed and immersed in Milli-Q water for 12 hours and dried at room temperature before measurement to confirm the absence of any preservative solution.

\subsubsection{Atomic Force Microscopy (AFM)}

Surface morphology and roughness of the RO membranes were analysed by AFM analysis (Lalia et al., 2013). It was conducted on a scanning probe microscope (model: NT-MDT NT-EGRA). Tapping mode of scanning was used to analyze the surface roughness of the RO membranes.

\subsubsection{Scanning Electron Microscopy (SEM)}

SEM (model: ULTRA plus, Carl Zeiss, Germany,) was used to observe the surface structure of the RO membranes (Lalia et al., 2013). Dried samples cut into pieces were put on sample stubs. Sputtering apparatus was used for sputtering a thin layer of gold on these samples. Finally, SEM images of prepared samples were observed at $15 \mathrm{kV}$ and $20,000 \times$ and $30,000 \times$ magnification.

\subsubsection{Fourier Transform Infrared (FTIR) Spectrometer}

FTIR analysis was performed using a FTIR spectrometer (model: Thermo Fisher Scientific Inc.). Sample of RO membrane was ground and mixed with anhydrous potassium bromide and subsequently pressed into a circular disk. FTIR spe- ctra was obtained for every membrane type, with each spectrum collected from 600 to $4000 \mathrm{~cm}^{-1}$. These spectra were subsequently improved for the penetration depth and background subtraction with the OMNIC software (Ver. 8.0, Thermo Fisher Scientific Inc.).

\subsubsection{Contact Angle Measurement}

The contact angle of dry and clean RO membrane surfaces was analysed using the sessile drop method to measure the hydrophilicity. A pure water drop $(3 \mathrm{ml})$ was placed on flat RO surface by microsyringe with a stainless steel needle. The contact angle between liquid drop and RO surface was measured by monochrome image, recorded by an interline camera of drop shape analyzer (DSA25, make: KRUSS) connected to a software. Average value of three samples were taken for calculation.

\section{Results and Discussion}

\subsection{RSM and ANOVA Analysis}

Analysis of variance (ANOVA) was employed to evaluate the adequacy of the selected model (Wang and Huang, 2014). ANOVA was used to analyse experimental data of RSM. Experimental response models were derived and used to find optimal values of the operating variables. Table 2 shows the CCD experimental design for RO membranes that was developed by Design Expert software (Stat-Ease, Inc, Minneapolis, $\mathrm{MN})$.

\subsubsection{Optimization of Water Recovery}

Graphical presentation of the data and analysis from RS$\mathrm{M}$ are presented in the form of RS plot. The comparative RS plots for water recovery as a function of different variables are shown in Figure 2(a-f).

As seen in Figure 2(a), at low and high values of temperature, water recovery increases with increase in pressure from 0.59 MPa to 0.79 MPa for CSM membrane. Similar trend is observed for Dow membrane for an increase in pressure (from $0.88 \mathrm{MPa}$ to $1.47 \mathrm{MPa}$ ) in Figure 2(b) and 0.59 $\mathrm{MPa}$ to 1.18 MPa for Vontron membrane in Figure 2(c). The water recovery increases apparently because higher pressure allows more flow of water through the membrane (Koyuncu et al., 2001; Sassi and Mujtaba, 2010). Effects of feed water concentration and $\mathrm{pH}$ on water recovery are not significant for CSM membrane (Figure 2d). However, at low and high $\mathrm{pH}$, water recovery decreases with concentration from $1500 \mathrm{mg} / \mathrm{L}$ to $35-$ $00 \mathrm{mg} / \mathrm{L}$ for Dow and Vontron membranes as shown in Figure 2(e and f). Lower water recovery is apparent because of higher salt concentration, causing the negative effect of concentration polarization and decreasing membrane water flux (Koyuncu et al., 2001). On the other hand, the effect of $\mathrm{pH}$ and temperature on water recovery are not significant in these cases because of the low susceptibility of polysulphone membrane to conformational variations in response to changes in temperature and $\mathrm{pH}$ (Arkhan-gelsky et al., 2007). The response sur- 
Table 2. Experimental Inputs and Responses of CSM, Dow and Vontron RO Membrane

\begin{tabular}{|c|c|c|c|c|c|c|c|c|c|c|c|c|c|}
\hline \multirow{3}{*}{ Run } & \multicolumn{4}{|c|}{ Input variables } & \multicolumn{9}{|c|}{ Responses } \\
\hline & \multirow{2}{*}{ A } & \multirow{2}{*}{ B } & \multirow{2}{*}{$\mathrm{C}$} & \multirow{2}{*}{$\mathrm{D}$} & \multicolumn{3}{|c|}{ Recovery (\%) } & \multicolumn{3}{|c|}{ Rejection (\%) } & \multicolumn{3}{|c|}{$\operatorname{SEC}\left(\mathrm{kWh} / \mathrm{m}^{3}\right)$} \\
\hline & & & & & CSM & Dow & Vontron & CSM & Dow & Vontron & $\mathrm{CSM}$ & Dow & Vontron \\
\hline 1 & -1 & -1 & -1 & -1 & 9.09 & 8.26 & 3.12 & 91.62 & 89.93 & 67.11 & 28.16 & 29.33 & 55 \\
\hline 2 & +1 & -1 & -1 & -1 & 6.98 & 10.39 & 4.23 & 90.22 & 89.77 & 82.59 & 28 & 23.39 & 43.21 \\
\hline 3 & -1 & +1 & -1 & -1 & 18.92 & 12.59 & 8.88 & 90.99 & 84.40 & 79.07 & 17.60 & 24.44 & 26.79 \\
\hline 4 & +1 & +1 & -1 & -1 & 20 & 16.11 & 12.39 & 89.19 & 85.50 & 85.58 & 17.60 & 19.25 & 21.11 \\
\hline 5 & -1 & -1 & +1 & -1 & 6.98 & 5.08 & 2.91 & 86.60 & 82.66 & 70 & 38.72 & 42.35 & 67.22 \\
\hline 6 & +1 & -1 & +1 & -1 & 8.84 & 5.50 & 3.52 & 85.14 & 83.64 & 80.75 & 29.94 & 38.89 & 53.78 \\
\hline 7 & -1 & +1 & +1 & -1 & 14.63 & 8.59 & 8.93 & 83.52 & 73.07 & 80.15 & 26.40 & 31.21 & 29.18 \\
\hline 8 & +1 & +1 & +1 & -1 & 17.83 & 11.22 & 10.63 & 78.33 & 76.40 & 80.99 & 22.47 & 25.48 & 24.87 \\
\hline 9 & -1 & -1 & -1 & +1 & 8.16 & 7.52 & 3.89 & 92.02 & 91.09 & 72.62 & 29.04 & 34.05 & 50 \\
\hline 10 & +1 & -1 & -1 & +1 & 9.09 & 8.81 & 5 & 92.08 & 90.74 & 86.21 & 29.04 & 27.31 & 41.72 \\
\hline 11 & -1 & +1 & -1 & +1 & 12.79 & 11.22 & 9.42 & 90.11 & 87.04 & 79.20 & 28 & 26.10 & 26.79 \\
\hline 12 & +1 & +1 & -1 & +1 & 17.65 & 17.06 & 12.64 & 90.03 & 82.26 & 82.64 & 20.53 & 21.90 & 20.64 \\
\hline 13 & -1 & -1 & +1 & +1 & 7.75 & 4.71 & 2.99 & 85.67 & 86.12 & 79.25 & 35.62 & 45.83 & 63.68 \\
\hline 14 & +1 & -1 & +1 & +1 & 8.92 & 5.20 & 3 & 86.39 & 86.18 & 84.08 & 32.17 & 40.10 & 48.40 \\
\hline 15 & -1 & +1 & +1 & +1 & 16.08 & 8.62 & 8.34 & 82.90 & 79.56 & 84.85 & 28.31 & 35 & 32.50 \\
\hline 16 & +1 & +1 & +1 & +1 & 18.03 & 9.75 & 9.12 & 83.31 & 81.67 & 86.42 & 24 & 27.84 & 26.73 \\
\hline 17 & $-\alpha$ & 0 & 0 & 0 & 10 & 8.17 & 5.16 & 89.16 & 82.81 & 72.42 & 29.92 & 32.13 & 44.25 \\
\hline 18 & $+\alpha$ & 0 & 0 & 0 & 15 & 11.35 & 8.86 & 87.16 & 81.91 & 88.11 & 20.53 & 22.34 & 27.31 \\
\hline 19 & 0 & $-\alpha$ & 0 & 0 & 5.88 & 3.45 & 0.85 & 89.61 & 87.33 & 61.26 & 37.55 & 46.93 & 80 \\
\hline 20 & 0 & $+\alpha$ & 0 & 0 & 24.14 & 16.61 & 13 & 84.92 & 70 & 75 & 19.11 & 30 & 25.06 \\
\hline 21 & 0 & 0 & $-\alpha$ & 0 & 10.01 & 12.02 & 8.59 & 93.53 & 87.84 & 85.31 & 20.53 & 20.93 & 27.31 \\
\hline 22 & 0 & 0 & $+\alpha$ & 0 & 9.09 & 7.46 & 5.24 & 83.90 & 79.21 & 82.41 & 27.20 & 40 & 43.50 \\
\hline 23 & 0 & 0 & 0 & $-\alpha$ & 12.82 & 9.14 & 6.68 & 84.27 & 78.85 & 86.77 & 25.34 & 27.50 & 34.68 \\
\hline 24 & 0 & 0 & 0 & $+\alpha$ & 9.52 & 7.51 & 6.34 & 90.34 & 88.77 & 90.99 & 30.80 & 31.09 & 36.67 \\
\hline 25 & 0 & 0 & 0 & 0 & 12.20 & 10.07 & 6.80 & 90.12 & 77.56 & 85.95 & 24.64 & 25.54 & 35.16 \\
\hline 26 & 0 & 0 & 0 & 0 & 12.73 & 8.99 & 6.98 & 92.00 & 82.10 & 84.72 & 25.14 & 25.54 & 34.22 \\
\hline 27 & 0 & 0 & 0 & 0 & 13.13 & 10.07 & 7.24 & 88.25 & 77.56 & 85 & 23.69 & 25.54 & 32.91 \\
\hline 28 & 0 & 0 & 0 & 0 & 11.28 & 8.99 & 6.89 & 88.93 & 82.10 & 83.91 & 28 & 25.54 & 34.68 \\
\hline 29 & 0 & 0 & 0 & 0 & 10.53 & 9.88 & 6.80 & 89.96 & 83.07 & 85.73 & 30.80 & 24.44 & 35.16 \\
\hline 30 & 0 & 0 & 0 & 0 & 12.50 & 9.88 & 6.72 & 90.15 & 83.07 & 86.43 & 24.64 & 24.44 & 35.65 \\
\hline
\end{tabular}

${ }^{*} \mathrm{~A}=$ Temperature, $\mathrm{B}=$ Feed Pressure, $\mathrm{C}=$ Feed Concentration, $\mathrm{D}=\mathrm{pH}$.

face indicates a general trend of enhancement in water recovery with increasing feed pressure. In contrast, water recovery decreases on increasing feed water concentrations.

Table 3 shows the ANOVA results for water recovery of CSM, Dow and Vontron RO membranes. F-values of 26.49, 24.08 and 212.80 for CSM, Dow and Vontron RO membranes respectively imply that the quadratic model is significant. The large $\mathrm{P}$ values $(>0.05)$ show that the $\mathrm{F}$-statistic is insignificant for all RO membranes, implying good correlation between the variables and process responses.

For the CSM RO membrane, ANOVA response for water recovery obtained from the response surface quadratic model shows that model term B is highly significant, whereas terms $A, B^{2}, C^{2}$ are significant. A high $R^{2}$ coefficient (close to unity) (Table 3 ) confirms a satisfactory fit of the quadratic model to the experimental data. The quadratic equation in terms of the coded factors for response on "water recovery" of CSM mem- brane is given as follows:

$$
\begin{aligned}
& \text { Water recovery }_{c s m}=12.06+0.96(A)+4.44(B) \\
& -0.23(C)-0.47(D)+0.58(A B)+0.21(A C) \\
& +0.30(A D)-0.12(B C)-0.55(B D)+0.61(C D) \\
& +0.20\left(A^{2}\right)+0.83\left(B^{2}\right)-0.54\left(C^{2}\right)-0.13\left(D^{2}\right)
\end{aligned}
$$

where $A$ is the temperature $\left({ }^{\circ} \mathrm{C}\right), B$ is the pressure $(\mathrm{MPa}), C$ is the concentration $(\mathrm{mg} / \mathrm{L})$ and $D$ is the $\mathrm{pH}$.

Table 3 shows that the model terms $B, C$ are highly significant, whereas terms $A, A B, A C$ are significant. Note that $R^{2}$ value is about 0.9574 , being close to unity, which represents an excellent fit. The quadratic equation in terms of the coded factors for response on "water recovery" of Dow membrane is given as follows: 

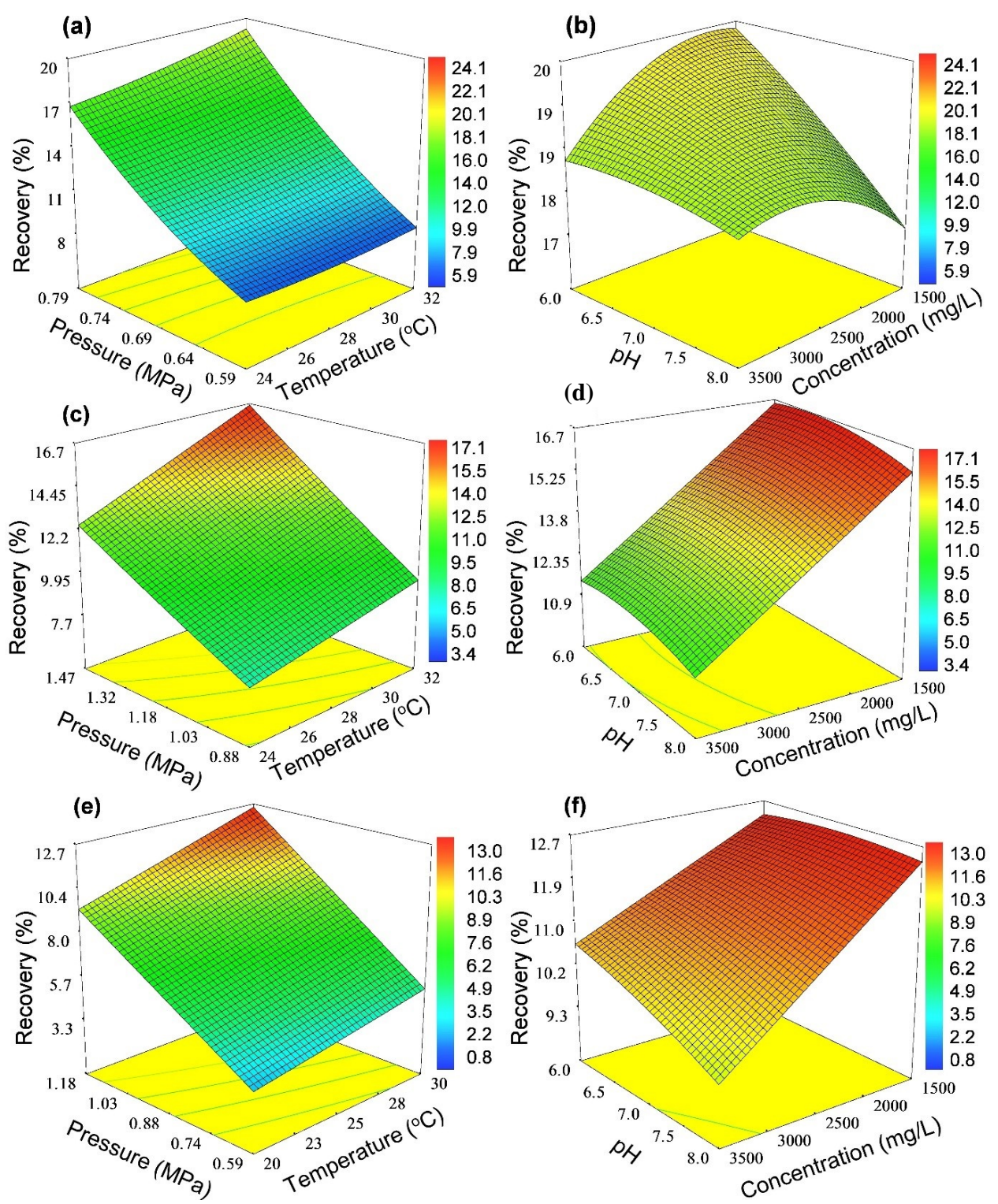

Figure 2. Response surface plots showing the effect of different variables on water recovery of CSM (a, b); Dow (c, d) and Vontron (e, f).

Water recovery $_{\text {Dow }}=9.65+0.99(A)+2.75(B)$

$-1.77(C)-0.34(D)+0.55(A B)-0.51(A C)$

$+2.57 E-0.03(A D)-0.27(B C)+0.070(B D)$

$+0.038(C D)+0.019\left(A^{2}\right)+0.087\left(B^{2}\right)$

$+0.014\left(C^{2}\right)-0.34\left(D^{2}\right)$

For the Vontron RO membrane, the ANOVA response for water recovery obtained from the response surface quadratic model shows that the model terms $A, B, C$ are highly significant, whereas terms $A B, A C, B C$ and $C D$ are significant.
The $R^{2}$ value of 0.9949 (99.49\%) represents an excellent fit of the regression model for water recovery of Vontron membrane (Table 3). The quadratic equation in terms of coded factors for reponse on "water recovery" of Vontron membrane, is given as follows:

$$
\begin{aligned}
& \text { Water recovery }_{\text {Vontron }}=6.90+0.81(A)+3.17(B) \\
& -0.70(C)-0.037(D)+0.40(A B)-0.37(A C) \\
& -0.11(A D)-0.16(B C)-0.15(B D)-0.30(C D) \\
& +0.022\left(A^{2}\right)+5.36 E-0.04\left(B^{2}\right)-1.48 E \\
& -0.03\left(C^{2}\right)-0.1\left(D^{2}\right)
\end{aligned}
$$


Table 3. ANOVA Result for RS Quadratic Model for Different Input Variables

\begin{tabular}{|c|c|c|c|c|c|c|c|c|}
\hline $\begin{array}{l}\text { Input } \\
\text { Variables }\end{array}$ & Membranes & Source & $\begin{array}{l}\text { Sum of } \\
\text { Squares }\end{array}$ & DF & $\begin{array}{l}\text { Mean } \\
\text { Square }\end{array}$ & F Value & $\mathrm{P}>\mathrm{F}$ & $\mathrm{R}^{2}$ \\
\hline \multirow{6}{*}{$\begin{array}{l}\text { Water } \\
\text { Recovery }\end{array}$} & \multirow[t]{2}{*}{ CSM RO } & Model & 553.6266 & 14 & 39.5447 & 26.4869 & $<0.0001^{* *}$ & \multirow[t]{2}{*}{0.9611} \\
\hline & & Lack of Fit & 17.6326 & 10 & 1.7632 & 1.8513 & $0.2576^{\#}$ & \\
\hline & \multirow[t]{2}{*}{ Dow RO } & Model & 296.9527 & 14 & 21.2109 & 24.0834 & $<0.0001^{* *}$ & \multirow[t]{2}{*}{0.9574} \\
\hline & & Lack of Fit & 11.8829 & 10 & 1.1882 & 4.4741 & $0.0560^{\#}$ & \\
\hline & \multirow[t]{2}{*}{ Vontron RO } & Model & 275.6002 & 14 & 19.6857 & 212.8065 & $<0.0001^{* *}$ & \multirow[t]{2}{*}{0.9949} \\
\hline & & Lack of Fit & 1.2166 & 10 & 0.1216 & 3.5595 & $0.0869^{\#}$ & \\
\hline \multirow[t]{6}{*}{ Salt Rejection } & \multirow[t]{2}{*}{ CSM RO } & Model & 333.2824 & 14 & 23.8058 & 13.1467 & $<0.0001^{* *}$ & \multirow[t]{2}{*}{0.9246} \\
\hline & & Lack of Fit & 18.9688 & 10 & 1.8968 & 1.1576 & $0.4628^{\#}$ & \\
\hline & \multirow[t]{2}{*}{ Dow RO } & Model & 659.8309 & 14 & 47.1307 & 7.1681 & $0.0003^{*}$ & \multirow[t]{2}{*}{0.8699} \\
\hline & & Lack of Fit & 63.9939 & 10 & 6.3993 & 0.9239 & $0.5740^{\#}$ & \\
\hline & \multirow[t]{2}{*}{ Vontron RO } & Model & 1279.2510 & 14 & 91.3750 & 34.1751 & $<0.0001^{* *}$ & \multirow[t]{2}{*}{0.9696} \\
\hline & & Lack of Fit & 35.8749 & 10 & 3.5874 & 4.2395 & $0.0622^{\#}$ & \\
\hline \multirow[t]{6}{*}{ SEC } & \multirow[t]{2}{*}{ CSM RO } & Model & 751.8794 & 14 & 53.7056 & 10.1417 & $<0.0001^{* *}$ & \multirow[t]{2}{*}{0.9044} \\
\hline & & Lack of Fit & 42.7727 & 10 & 4.2772 & 0.5833 & $0.7811^{\#}$ & \\
\hline & \multirow[t]{2}{*}{ Dow RO } & Model & 1598.1530 & 14 & 114.1538 & 132.5644 & $<0.0001^{* *}$ & \multirow[t]{2}{*}{0.9919} \\
\hline & & Lack of Fit & 11.3289 & 10 & 1.1328 & 3.5674 & $0.0865^{\#}$ & \\
\hline & \multirow[t]{2}{*}{ Vontron RO } & Model & 5865.0270 & 14 & 418.9305 & 215.7788 & $<0.0001^{* *}$ & \multirow[t]{2}{*}{0.9950} \\
\hline & & Lack of Fit & 24.3826 & 10 & 2.4382 & 2.5722 & $0.1544 \#$ & \\
\hline
\end{tabular}

DF: Degree of freedom, $* *=$ Highly significant, $*=$ Significant, $\#=$ Not significant.

\subsubsection{Optimization of Salt Rejection}

Three dimensional comparative RS plots for salt rejection as a function of different input variables are depicted in Figure 3. At high and low values of temperature, the salt rejection does not show any significant change with pressure for either CSM or Dow membranes. However, it increases at a low value of pressure $(0.59 \mathrm{MPa})$ with temperature ranging from 20 ${ }^{\circ} \mathrm{C}$ to $30{ }^{\circ} \mathrm{C}$ for Vontron membrane (Figure $3 \mathrm{e}$ ). This is apparently because higher diffusion rate of solute through the membrane is possible as the solubility increases with temperature (Arora et al., 2004; Gedam et al., 2012). Similarly, at high and low values of temperature, salt rejection increases with the pressure from $0.59 \mathrm{MPa}$ to $1.03 \mathrm{MPa}$ for Vontron membrane. This is because the rejection increases along with operating pressure due to the higher formation of concentration polarization at the membrane interface (Tu et al., 2010; Zulkali et al., 2005). At low values of $\mathrm{pH}$, salt rejection decreases with feed water concentration that ranges from $1500 \mathrm{mg} / \mathrm{L}$ to 3500 $\mathrm{mg} / \mathrm{L}$ for all three RO membranes (Figures $3 \mathrm{~b}, 3 \mathrm{~d}$, and $3 \mathrm{f}$ ). This is because at high feed salinity, the salt passage increases (Bartels et al., 2005). However, at high values of $\mathrm{pH}$, the salt rejection does not show any significant change with feed water concentration for all RO membranes.

This analysis shows that the salt rejection in a small scale $\mathrm{RO}$ plant would be better at low feed concentration, low $\mathrm{pH}$ and high pressure. CSM (89.2\%) and vontron (89.66\%) among the three RO membranes show the better performance for the salt rejection.

In Table 3, ANOVA results show F-values of 13.14, 7.16 and 34.17 for salt rejection of CSM, Dow and Vontron RO membranes. This implies that the quadratic model is signifycant. The large $\mathrm{P}$ values $(>0.05)$ shows that the F-statistic values are insignificant for all RO membranes, implying significant model correlation between the variables and process responses.

For the CSM RO membrane, ANOVA response for salt rejection obtained from the response surface quadratic model shows that the model term $C$ is highly significant, whereas terms $B, D, A D, B^{2}$ and $D^{2}$ are significant. Note that $R^{2}$ value is about 0.9246 , being close to unity, which represents an excellent fit (Table 3). Through multiple regression analysis on the experimental data (Wang and Huang, 2015), response for the salt rejection of CSM RO membranes may be predicted by the following second-order polynomial equation in term of coded values:

$$
\begin{aligned}
& \text { Salt rejection }_{c s m}=89.90-0.53(A)-1.28(B) \\
& -3.07(C)+0.79(D)-0.29(A B)-0.14(A C) \\
& +0.69(A D)-0.63(B C)+0.11(B D)+0.15(C D) \\
& -0.51\left(A^{2}\right)-0.74\left(B^{2}\right)-0.38\left(C^{2}\right)-0.73\left(D^{2}\right)
\end{aligned}
$$

where $A$ is the temperature $\left({ }^{\circ} \mathrm{C}\right), B$ is the pressure (MPa), $C$ is the concentration $(\mathrm{mg} / \mathrm{L})$ and $D$ is the $\mathrm{pH}$.

For the Dow RO membrane, ANOVA response for salt rejection obtained from the response surface quadratic model shows that model terms $B, C$ are highly significant, whereas terms $D, C^{2}$ and $D^{2}$ are significant. A high $R^{2}$ coefficient (close to unity) (Table 3 ) confirms a satisfactory fit of the quadratic model to the experimental data. The quadratic equation in terms of the coded factors for response on "salt rejection" of Dow membrane is given as follows: 

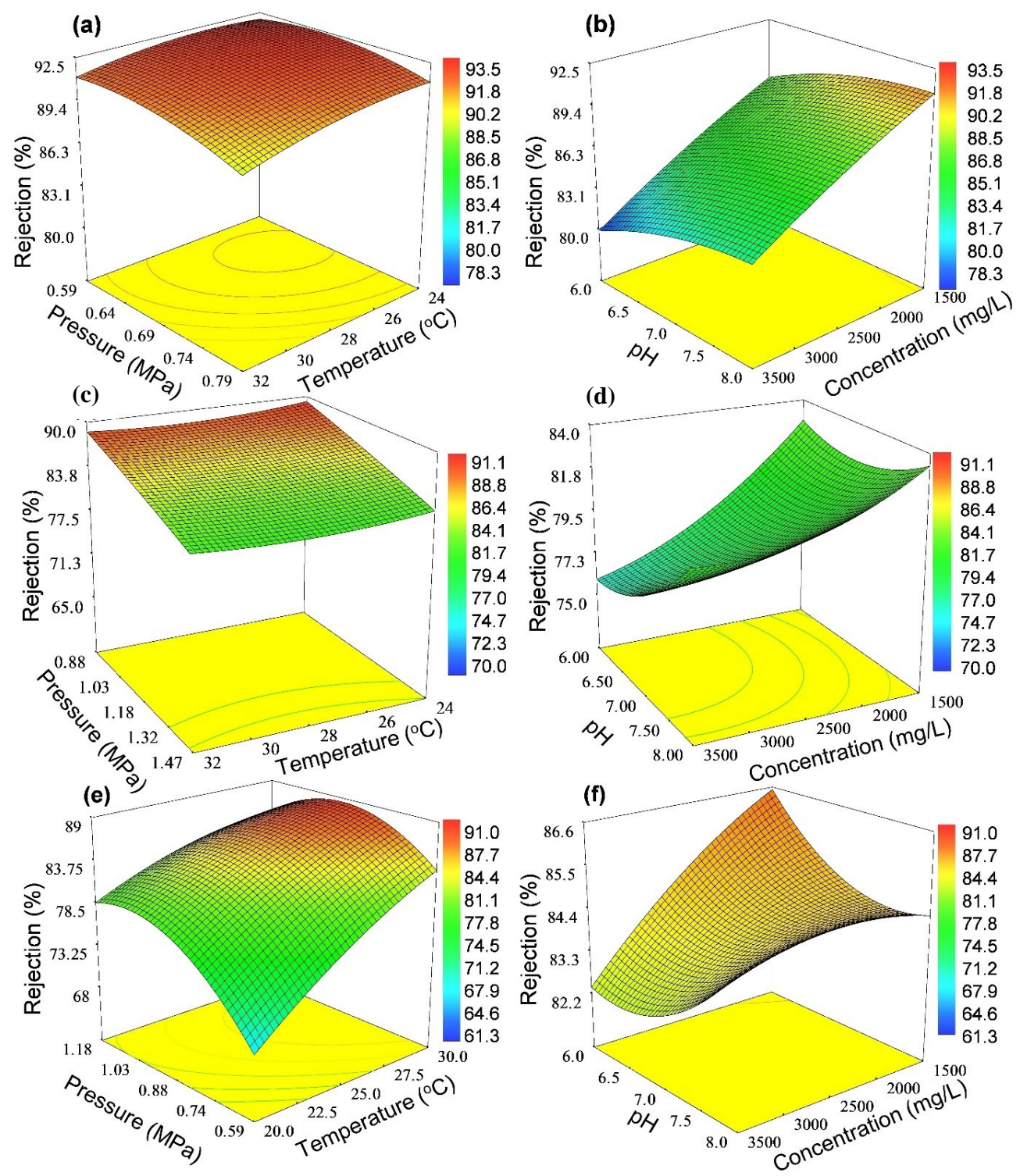

Figure 3. Response surface plots showing the effect of different variables on salt rejection of CSM (a, b); Dow (c, d) and Vontron (e, f).

Salt rejection $_{\text {Dow }}=80.91+0.022(A)-3.54(B)$

$-2.86(C)+1.63(D)+0.077(A B)+0.67(A C)$

$-0.51(A D)-0.35(B C)+0.19(B D)+1.01(C D)$

$+0.74\left(A^{2}\right)-0.18\left(B^{2}\right)+1.04\left(C^{2}\right)+1.11\left(D^{2}\right)$

For the Vontron RO membrane, ANOVA response for salt rejection obtained from the response surface quadratic model shows that the model terms $A, B, B^{2}$ are highly significant, whereas terms $D, A B, A C, B D, C D, A^{2}$ and $D^{2}$ are significant. The $R^{2}$ value of 0.9696 (close to unity) confirms a satisfactory fit of the quadratic model to the experimental data (Table 3). The quadratic equation in terms of the coded factors for re- sponse on "salt rejection" of Vontron membrane is given as follows:

$$
\begin{aligned}
& \text { Salt rejection }_{\text {Vontron }}=85.29+3.68(A)+2.66(B) \\
& +0.24(C)+1.56(D)-2.02(A B)-1.31(A C) \\
& -0.64(A D)+0.023(B C)-0.90(B D)+1.02(C D) \\
& -1.29\left(A^{2}\right)-4.32\left(B^{2}\right)-0.39\left(C^{2}\right)+0.87\left(D^{2}\right)
\end{aligned}
$$

\subsubsection{Optimization of SEC}

The RS plots in Figure 4 illustrate the effect of temperature, pressure, $\mathrm{pH}$ and concentration on SEC for all the three RO membranes. At low and high temperature of feed water, 
SEC decreases with pressure from $0.59 \mathrm{MPa}$ to $0.79 \mathrm{MPa}$ for CSM membrane, from $0.88 \mathrm{MPa}$ to $1.32 \mathrm{MPa}$ for Dow membrane and from $0.59 \mathrm{MPa}$ to $1.18 \mathrm{MPa}$ for Vontron membrane (Figures $4 \mathrm{a}, 4 \mathrm{c}$ and $4 \mathrm{e}$ ). This is because the permeate flow rate and the recovery increases at the same time as the applied pressure increases. Also, a decrease in SEC compensates largely for the energy required to apply a higher desalination pressure (Laborde et al., 2001). At a low and high value of $\mathrm{pH}$, SEC increases with concentration ranging from $1500 \mathrm{mg} / \mathrm{L}$ to 3500 $\mathrm{mg} / \mathrm{L}$ for all three RO membranes (Figures $4 \mathrm{~b}, 4 \mathrm{~d}$, and $4 \mathrm{f}$ ). This trend has been observed because the minimum value of required energy increases linearly as a function of the solution concentration (Laborde et al., 2001). It is considerable to note that the high rejection of Vontron membrane as compared to the other membranes results in higher concentration polarization, higher osmotic pressure and consequently lower flux which directly influences SEC (Richards et al., 2011). Based on the above analysis, it may be predicted that small scale RO plants show a low SEC at higher pressure and lesser feed concentration.

ANOVA results presented in Table 3 show F-values of 10.14, 132.56 and 215.77 for SEC of CSM, Dow and Vontron RO membranes. This implies that the quadratic model is significant. The large $\mathrm{P}$ values $(>0.05)$ show that the F-statistic values are insignificant for all $\mathrm{RO}$ membranes, implying good correlation between the variables and process responses. Table 3 shows that the model term $B$ is highly significant, whereas $C$ and $D$ are significant terms. A high $\mathrm{R}^{2}$ coefficient (close to unity) confirms a satisfactory fit of the quadratic model to the experimental data. Through multiple regression analysis on the experimental data, response for the SEC of CSM RO membranes may be predicted by the following second-order polynomial equation in term of coded values:

$$
\begin{aligned}
& S E C_{c s m}=26.15-1.95(A)-4.28(B)+2.21(C) \\
& +1.20(D)-0.21(A B)-0.80(A C)-0.15(A D) \\
& -0.30(B C)+0.98(B D)-0.79(C D)-0.089\left(A^{2}\right) \\
& +0.69\left(B^{2}\right)-0.43\left(C^{2}\right)+0.62\left(D^{2}\right)
\end{aligned}
$$

where $A, B, C$ and $D$ are the coded variables for temperature, pressure, concentration and $\mathrm{pH}$, respectively.

Table 3 shows that model terms $A, B, C, D, B C, B^{2}, C^{2}$, $D^{2}$ are highly significant, whereas term $A^{2}$ is significant. Note that $R^{2}$ value is about 0.9919 , which being close to unity, represents an excellent fit of the regression model for SEC of Dow membrane. The quadratic equation in terms of the coded factors for response on "SEC" of Dow membrane is given as follows:

$$
\begin{aligned}
& S E C_{D o w}=25.17-2.66(A)-4.33(B)+4.96(C) \\
& +1.29(D)-0.026(A B)-1.663 E-0.04(A C) \\
& -0.22(A D)-1.58(B C)-0.18(B D)-0.13(C D) \\
& +0.42\left(A^{2}\right)+3.23\left(B^{2}\right)+1.23\left(C^{2}\right)+0.93\left(D^{2}\right)
\end{aligned}
$$

For the Vontron RO membrane, ANOVA response for SEC obtained from the response surface quadratic model (Table 3 ) shows that the model terms $A, B, C, B^{2}$ are highly significant, whereas terms $A B, B C$ and $B D$ are significant. The $R^{2}$ value of $0.9950(99.5 \%)$ represents an excellent fit of the regression model for SEC of Vontron membrane. The quadratic equation in terms of coded factors for response on "SEC" of Vontron membrane is given as follows:

$$
\begin{aligned}
& S E C_{\text {Vontron }}=34.63-4.36(A)-13.51(B)+3.90(C) \\
& -0.28(D)+1.68(A B)-0.43(A C)-0.016(A D) \\
& -1.58(B C)+1.26(B D)+0.20(C D)+0.23\left(A^{2}\right) \\
& +4.41\left(B^{2}\right)+0.13\left(C^{2}\right)+0.20\left(D^{2}\right)
\end{aligned}
$$

\subsection{Multiple Response Optimization}

Membrane optimisation was carried out by the RSM through regression analysis to achieve the maximum recovery, highest salt rejection and the lowest SEC. Predicted numerical optimization of input parameters was obtained and is presented in Table 4. Model predictions validated by the confirmation run at these optimal process conditions, are in agreement with the predicted responses. Less than $6 \%$ error for each response showed the reliability of CCD optimisation process. These results demonstrate an improvement in the individual RO membrane employing optimized input parameters. It can be easily concluded by the above analysis that CSM RO membrane shows the best performance at $31.92{ }^{\circ} \mathrm{C}$ temperature, $0.78 \mathrm{MPa}$ pressure, $1500 \mathrm{mg} / \mathrm{L}$ feed salt concentration and $6.53 \mathrm{pH}$ (very near to the actual i.e. 6.7 ) with $20.24 \%$ water recovery, $90.22 \%$ salt rejection and $17.87 \mathrm{kWh} / \mathrm{m}^{3}$ of SEC (Table 4), as compared to Dow and Vontron RO membranes.

Removal efficiency of major ions of validation experiments was studied for divalent ions $\left(93.95 \% \mathrm{Ca}^{2+}, 94.10 \% \mathrm{Mg}^{2+}\right.$ and $94.7 \% \mathrm{SO}_{4}{ }^{2+}$ ) and it was found to be higher as compared to monovalent ions $\left(89.94 \% \mathrm{Na}^{+}, 92.02 \% \mathrm{Cl}^{-}, 82.15 \% \mathrm{NO}^{3-}\right.$, $\left.87.15 \% \mathrm{HCO}^{3-}\right)$.

\subsection{Membrane Characterization}

Surface characterization was carried out by different measurement techniques. Surface roughness of three RO membranes were measured by AFM analysis as shown in Figure 5. The in-plane $x$ and $y$ scales are $10 \mu \mathrm{m} \times 10 \mu \mathrm{m}(1 \mu \mathrm{m} / \mathrm{div})$, while the $\mathrm{z}$ axis varies with respect to the surface roughness. AFM analysis reveals that the RMS ( $R q$ ) roughness value of the RO membranes varies from $35 \mu \mathrm{m}$ to nearly $55 \mu \mathrm{m}$. The CSM RO membrane was found to be the smoothest, with an RMS (Rq) value of $33.99 \mu \mathrm{m}$. Total surface area of the membrane increases with surface roughness which leads to the accumulation of foulants at the ridge-valley structure of the surface. The AFM technique has proved that rough surfaces are more vulnerable to fouling which causes decline in flux and salt rejection (Vrijenhoek et al., 2001).

SEM images of all virgin RO membranes exhibited typi- 

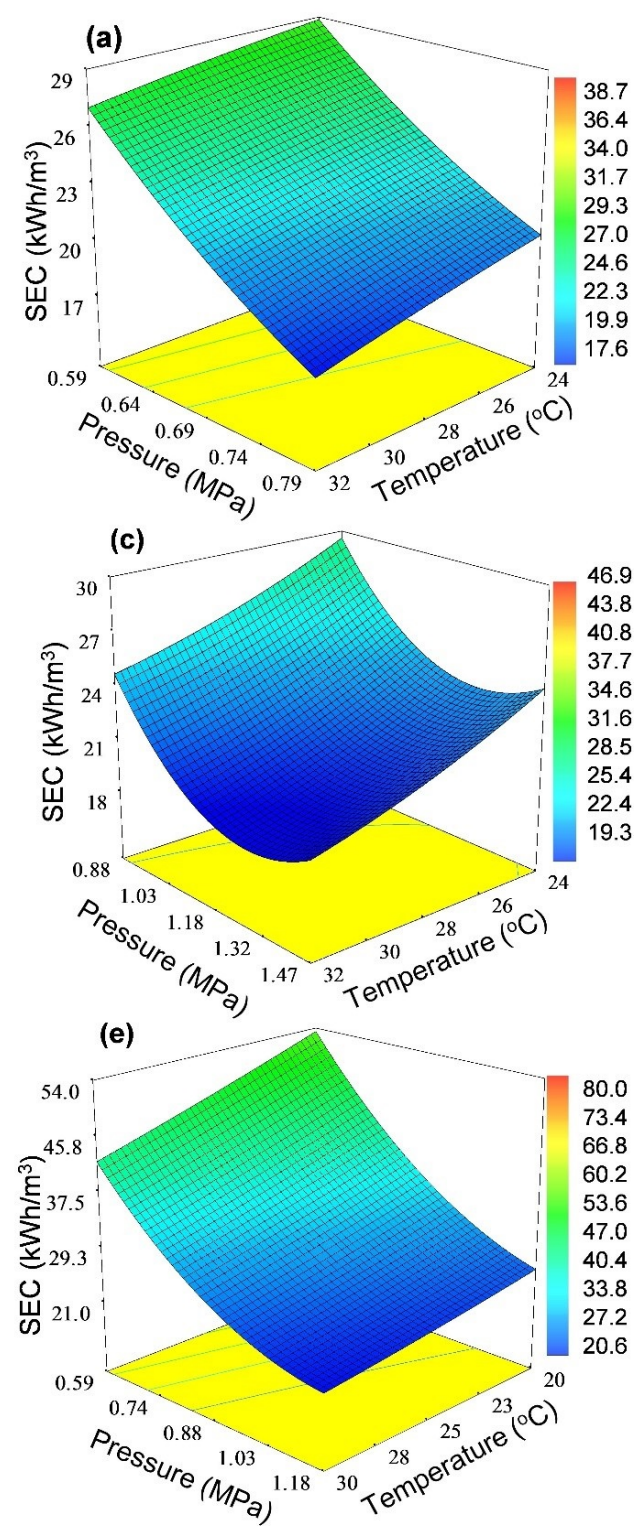
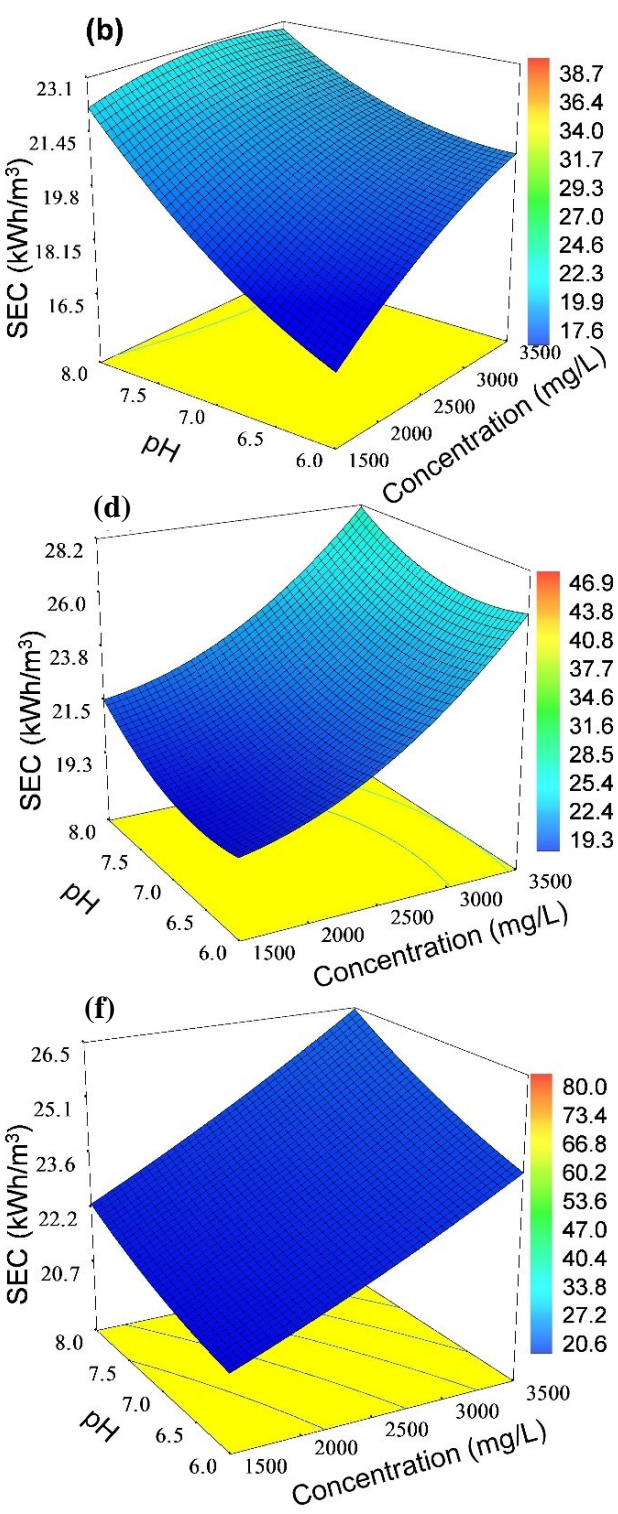

Figure 4. Response surface plots showing the effect of different variables on SEC of CSM (a, b); Dow (c, d) and Vontron $(\mathrm{e}, \mathrm{f})$.

Table 4. Multiple Response Optimizations with RSM of Different RO Membranes

\begin{tabular}{|c|c|c|c|c|c|c|c|c|c|c|}
\hline \multirow[b]{2}{*}{ Parameter } & \multicolumn{4}{|c|}{ Optimized input parameter } & \multicolumn{3}{|c|}{ RSM prediction } & \multicolumn{3}{|c|}{$\begin{array}{l}\text { Confirmation experiment under } \\
\text { optimized conditions }\end{array}$} \\
\hline & $\begin{array}{l}\text { Temperature } \\
\left({ }^{\circ} \mathrm{C}\right)\end{array}$ & $\begin{array}{l}\text { Feed } \\
\text { Pressure } \\
(\mathrm{MPa})\end{array}$ & $\begin{array}{l}\text { Feed } \\
\text { Concentration } \\
(\mathrm{mg} / \mathrm{L})\end{array}$ & $\mathrm{pH}$ & $\begin{array}{l}\text { Recovery } \\
(\%)\end{array}$ & $\begin{array}{l}\text { Rejection } \\
(\%)\end{array}$ & $\begin{array}{l}\mathrm{SEC} \\
\left(\mathrm{kWh} / \mathrm{M}^{3}\right)\end{array}$ & $\begin{array}{l}\text { Recovery } \\
(\%)\end{array}$ & $\begin{array}{l}\text { Rejection } \\
(\%)\end{array}$ & $\begin{array}{l}\text { SEC } \\
\left(\mathrm{kWh} / \mathrm{M}^{3}\right)\end{array}$ \\
\hline $\mathrm{CSM}$ & 31.92 & 0.78 & 1500 & 6.53 & 19.25 & 89.2 & 17.6 & 20.24 & 90.22 & 17.87 \\
\hline Dow & 32 & 1.43 & 1500 & 6.14 & 16.1 & 82.53 & 18.99 & 17.12 & 82.42 & 19.3 \\
\hline Vontron & 30 & 1.18 & 1518 & 6.73 & 12.75 & 89.66 & 19.02 & 13.37 & 91.17 & 20.04 \\
\hline
\end{tabular}



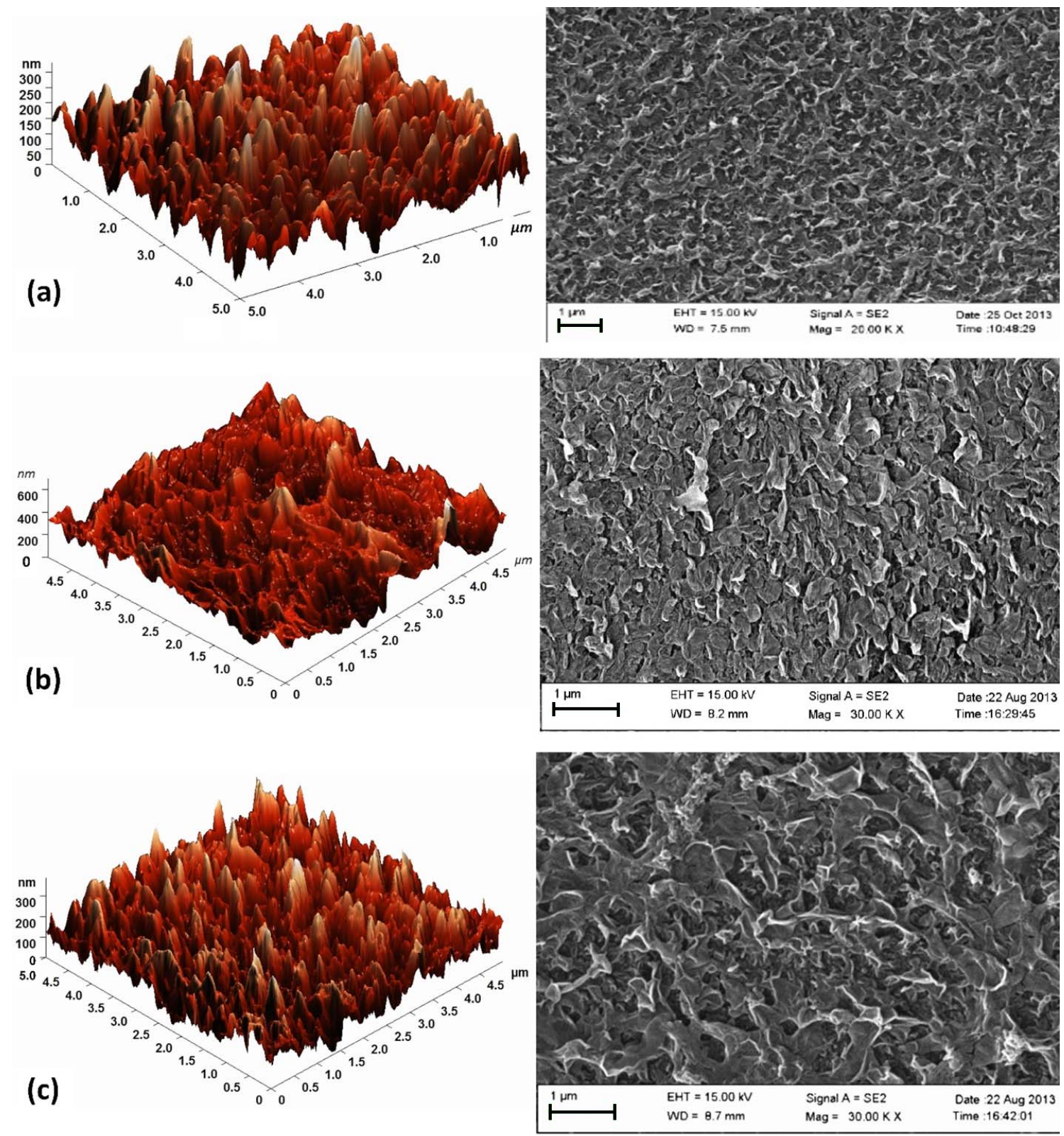

Figure 5. AFM and FE-SEM images of different RO membrane (a) CSM (b) Dow and (c) Vontron.

cal symmetric morphology with no significant difference as shown in Figure 5.

In order to authenticate functional groups on the membrane surfaces, FTIR analysis spectra were obtained for each virgin membranes and shown in Figure 6. These spectra are of wave numbers ranging between 500 and $4000 \mathrm{~cm}^{-1}$. The broad band around $3435.36 \mathrm{~cm}^{-1}$ is a complex one due to the overlapping of stretching vibration of $\mathrm{N}-\mathrm{H}$ and carboxylic groups and additional groups (such as $\mathrm{O}-\mathrm{H}$ groups) from the coating layer.

Also, IR spectra of all RO membranes were observed to be very similar to the poly (aryl) ether as shown in Figure 6 .
Therefore, it can be predicted that top layer of all RO membranes would be constituted of polyether sulphone.

Membrane hydrophilic-hydrophobic properties are based on a contact angle between the liquid-gas tangent and membrane-liquid boundary (Tarboush et al., 2008). Usually RO membrane materials having high contact angle are prone to adsorption of the various solutes. In this study, contact angle analysis was carried out by drop shape analyzer instrument (DSA25, make: KRUSS).

It had been shown earlier that RO membrane fouling, improved flux during operation and the surface roughness are strongly correlated to each other, The hydrophilic RO mem- 


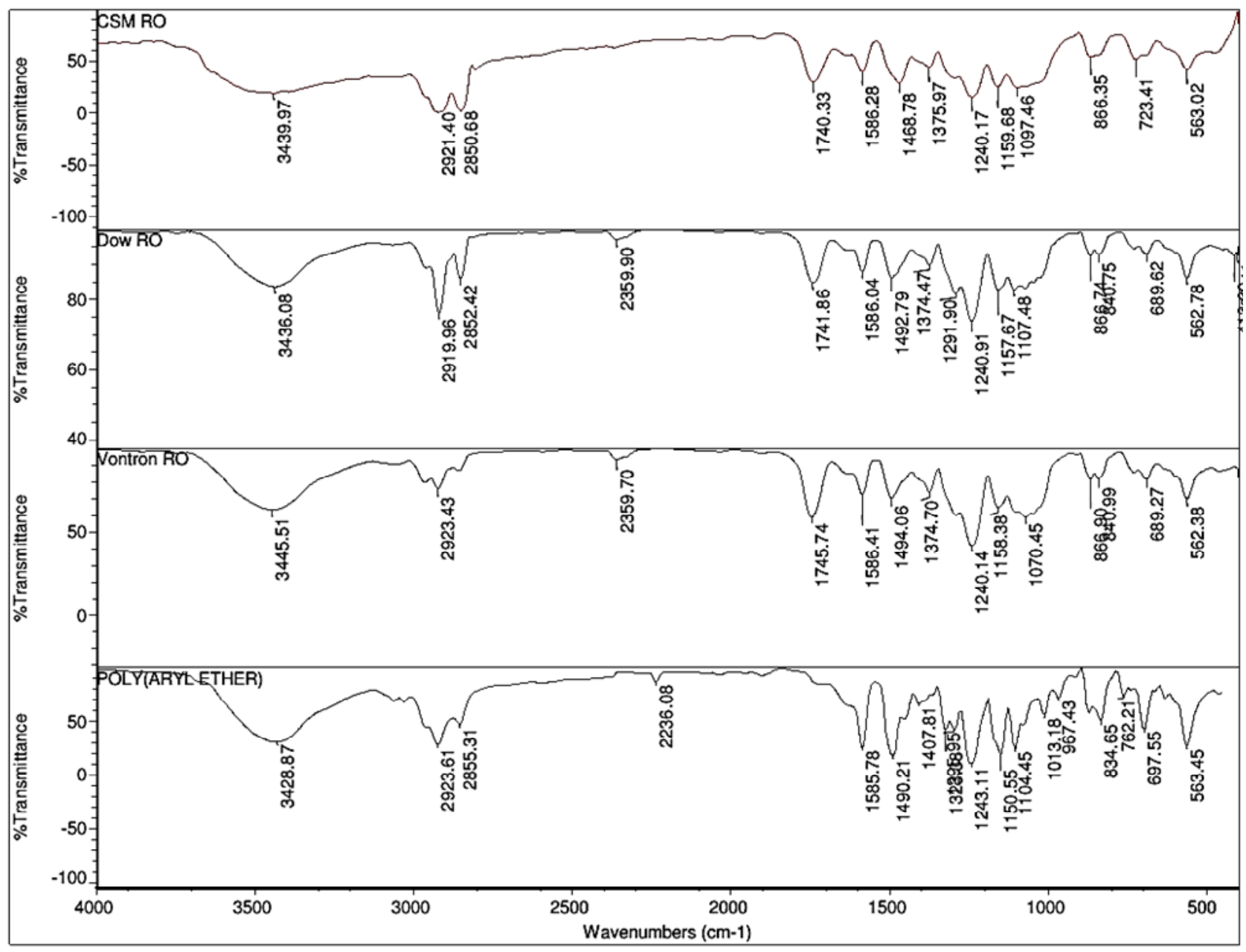

Figure 6. FTIR spectra of virgin CSM, Dow and Vontron RO membranes matched with the spectra of poly (aryl ether).

branes with smoother surfaces are less prone to adsorption of various solutes (inorganic fouling) compared to the relatively more hydrophobic and rougher membranes (Elimelech et al., 1997). The smaller contact angle (higher hydrophilicity) and smoother surface (Lowest RMS value) of CSM RO membrane might be the reason of its better performance.

\section{Conclusions}

It is necessary to optimize the small scale RO membranes in terms of recovery, rejection along with specific energy consumption. Optimization experiments by using CCD of RSM reveals that among all three commercial RO membranes, CSM membrane showed the best performance and the optimal conditions obtained were $6.53 \mathrm{pH}, 1500 \mathrm{mg} / \mathrm{L}$ concentration, $0.78 \mathrm{MPa}$ pressure and $31.94{ }^{\circ} \mathrm{C}$ temperature with the predicted results of water recovery, salt rejection and SEC of $19.25 \%, 89.21 \%$ and $17.60 \mathrm{kWh} / \mathrm{m}^{3}$, respectively. FE-SEM, AFM, contact angle measurement and FTIR proved to be valuable tools for characterization of RO membrane surface. When used together, these characterization tools provided str- ong explanation for better performance of small scale RO membranes. From FTIR analysis, it could be predicted that top layer of all RO membranes may be made from polyether sulphone. The lesser contact angle and smoother surface further contributed to the better performance of CSM RO membrane.

The presented methodology highlights a desirable approach for optimizing different RO membranes available in the market to make the RO systems economically viable and efficient.

Acknowledgments. This work was carried out by the financial support given by Ministry of Drinking Water and Sanitation, New Delhi, India under letter no. W-11035/24/2010-WQ (R\&D)-TS. We would also like to thank all those involved in this project.

\section{References}

Adams, G., and Bubucis, P. (1998). Calculating an artificial sea water formulation using spreadsheet matrices. Aquar. Sci. and conserv., 2(1), 35-41. http://dx.doi.org/10.1023/A:1009624710083

Arkhangelsky, E., Kuzmenko, D., and Gitis, V. (2007). Impact of ch- 
emical cleaning on properties and functioning of polyethersulfone membranes. J. Membr. Sci., 305(1-2), 176-184. http://dx.doi.org/ 10.1016/j.memsci.2007.08.007

Arora, M., Maheshwari, R.C., Jain, S.K., and Gupta, A. (2004). Use of membrane technology for potable water production. Desalination, 170(2), 105-112. http://dx.doi.org/10.1016/j.desal.2004.02. 096

Bartels, C., Franks, R., Rybar, S., Schierach, M., and Wilf, M. (2005). The effect of feed ionic strength on salt passage through reverse osmosis membranes. Desalination, 184(1-3), 185-195. http://dx. doi.org/10.1016/j.desal.2005.04.032

Bezerra, M.A., Santelli, R.E., Oliveira, E.P., Villar, L.S., and Escaleira, L.A. (2008). Response surface methodology (RSM) as a tool for optimization in analytical chemistry. Talanta, 76(5), 965977. http://dx.doi.org/10.1016/j.talanta.2008.05.019

Bohdziewicz, J., Bodzek, M., and Wạsik, E. (1999). The application of reverse osmosis and nanofiltration to the removal of nitrates from groundwater. Desalination, 121(2), 139-147. http://dx.doi. org/10.1016/S0011-9164(99)00015-6

Chakraborty, S., Dasgupta, J., Farooq, U., Sikder, J., Drioli, E., and Curcio, S. (2014). Experimental analysis, modeling and optimization of chromium (VI) removal from aqueous solutions by polymer enhanced ultrafiltration. J. Membr. Sci., 456(0), 139-154. http://dx.doi.org/10.1016/j.memsci.2014.01.016

Champidi, P., Stamatis, G., and Zagana, E. (2011). Groundwater quality assessment and geogenic and anthropogenic effect estimation in Erasinos Basin (E. Attica). Eur. Water, 33, 11-27

Elfil, H., Hamed, A., and Hannachi, A. (2007). Technical evaluation of a small-scale reverse osmosis desalination unit for domestic water. Desalination, 203(1-3), 319-326. http://dx.doi.org/10.1016/j. desal.2006.03.530

Elimelech, M., Xiaohua, Z., Childress, A.E., and Seungkwan, H. (1997). Role of membrane surface morphology in colloidal fouling of cellulose acetate and composite aromatic polyamide reverse osmosis membranes. J. Membr. Sci., 127(1), 101-109. http://dx.doi. org/10.1016/S0376-7388(96)00351-1

Elsaid, K., Bensalah, N., and Abdel-Wahab, A. (2012). Inland desalination: Potentials and challenges, in Z. N. A. S. Naveed (Ed.), Advances in Chemical Engineering, InTech.

Ferreira, S.L.C., Bruns, R.E., da Silva, E.G.P., dos Santos, W.N.L., Quintella, C.M., David, J.M., de Andrade, J.B., Breitkreitz, M.C., Jardim, I.C.S.F., and Neto, B.B. (2007a). Statistical designs and response surface techniques for the optimization of chromategraphic systems. J. Chromatogr, 1158(1-2), 2-14. http://dx.doi.org/ 10.1016/j.chroma.2007.03.051

Ferreira, S.L.C., Bruns, R.E., da Silva, E.G.P., dos Santos, W.N.L., Quintella, C.M., David, J.M., de Andrade, J.B., Breitkreitz, M.C., Jardim, I.C.S.F. and Neto, B.B. (2007b). Statistical designs and response surface techniques for the optimization of chromategraphic systems. J. Chromatogr., 1158(1-2), 2-14. http://dx.doi. org/10.1016/j.chroma.2007.03.051

Gedam, V.V., Patil, J.L., Kagne, S., Sirsam, R.S., and Labhasetwar, P. (2012). Performance evaluation of polyamide reverse osmosis membrane for removal of contaminants in ground water collected from chandrapur district. J. Membr. Sci. Technol., 2(3), 2-5. http:// dx.doi.org/10.4172/2155-9589.1000117

Hamouda, S.B., Akhtar, F.H., and Elfil, H. (2013). Diagnosis of small capacity reverse osmosis unit for desalinated tap water. Desalination Water Treat., 1-9. http://dx.doi.org/10.1080/19443994. 2013.822334

Idris, A., Kormin, F., and Noordin, M.Y. (2006). Application of response surface methodology in describing the performance of thin film composite membrane. Sep. Purif. Technol., 49(3), 271-280. http://dx.doi.org/10.1016/j.seppur.2005.10.010
Joyce, A., Loureiro, D., Rodrigues, C., and Castro, S. (2001). Small reverse osmosis units using PV systems for water purification in rural places. Desalination, 137(1-3), 39-44. http://dx.doi.org/10. 1016/S0011-9164(01)00202-8

Khayet, M., Cojocaru, C., and Essalhi, M. (2011). Artificial neural network modeling and response surface methodology of desalination by reverse osmosis. J. Membr. Sci., 368, 202-214. http://dx.doi. org/10.1016/j.memsci.2010.11.030

Khayet, M., Cojocaru, C., and Essalhi, M. (2011a). Artificial neural network modeling and response surface methodology of desalination by reverse osmosis. J. Membr. Sci., 368(1-2), 202-214. http:// dx.doi.org/10.1016/j.memsci.2010.11.030

Khayet, M., Cojocaru, C., and Essalhi, M. (2011b). Artificial neural network modeling and response surface methodology of desalination by reverse osmosis. J. Membr. Sci., 368(1-2), 202-214. http://dx.doi.org/10.1016/j.memsci.2010.11.030

Koutsou, C.P., Karabelas, A.J., and Kostoglou, M. (2015). Membrane desalination under constant water recovery -- The effect of module design parameters on system performance. Sep. Purif. Technol., 147(0), 90-113. http://dx.doi.org/10.1016/j.seppur.2015.04.012

Koyuncu, I., Yazgan, M., Topacik, D., and Sarikaya, H.Z. (2001). Evaluation of the low pressure RO and NF membranes for an alternative treatment of Buyukcekmece Lake. Water Sci. Technol. Water Supply, 1(1), 107-115

Laborde, H.M., França, K.B., Neff, H., and Lima, A.M.N. (2001). Optimization strategy for a small-scale reverse osmosis water desalination system based on solar energy. Desalination, 133(1), 112. http://dx.doi.org/10.1016/S0011-9164(01)00078-9

Lalia, B.S., Kochkodan, V., Hashaikeh, R., and Hilal, N. (2013). A review on membrane fabrication: Structure, properties and performance relationship. Desalination, 326(0), 77-95. http://dx. doi.org/10.1016/j.desal.2013.06.016

Mane, P.P., Park, P.K., Hyung, H., Brown, J.C., and Kim, J.H. (2009). Modeling boron rejection in pilot- and full-scale reverse osmosis desalination processes. J. Membr. Sci., 338(1-2), 119-127. http://dx. doi.org/10.1016/j.memsci.2009.04.014

Mehdizadeh, H. (2006). Membrane desalination plants from an energy-exergy viewpoint. Desalination, 191(1-3), 200-209. http:// dx.doi.org/10.1016/j.desal.2005.06.037

Montgomery, D.C. (2004). Design and Analysis of Experiments, Wiley, New York.

Qin, X.S., Huang, G.H., and Chakma, A. (2008). Modeling groundwater contamination under uncertainty: A factorial-design-based stochastic approach. J. Environ. Inf., 11(1), 11-20.

Rahardianto, A., Gao, J., Gabelich, C.J., Williams, M.D., and Cohen, Y. (2007). High recovery membrane desalting of low-salinity brackish water: Integration of accelerated precipitation softening with membrane RO. J. Membr. Sci., 289(1-2), 123-137. http://dx. doi.org/10.1016/j.memsci.2006.11.043

Razali, N.F., Mohammad, A.W., Hilal, N., Leo, C.P., and Alam, J. (2013). Optimisation of polyethersulfone/polyaniline blended membranes using response surface methodology approach. Desalina -tion, 311(0), 182-191. http://dx.doi.org/10.1016/j.desal.2012.11. 033

Richards, L.A., Richards, B.S., and Schäfer, A.I. (2011). Renewable energy powered membrane technology: Salt and inorganic contaminant removal by nanofiltration/reverse osmosis. J. Membr. Sci., 369(1-2), 188-195. http://dx.doi.org/10.1016/j.memsci.2010.11.06

Sassi, K.M., and Mujtaba, I.M. (2010). Simulation and optimization of full scale reverse osmosis desalination plant, in S. Pierucci and G. B. Ferraris (Eds.), Computer Aided Chemical Engineering, vol. 28, pp. 895-900, Elsevier.

Şen, Z. (2004). Solar energy in progress and future research trends. Prog. Energy Combust. Sci., 30(4), 367-416. http://dx.doi.org/10. 
1016/j.pecs.2004.02.004

Shuman, B. (1995). A Comparison of Response Surface Methodology and a One-factor-at-a-time Approach as Calibration Techniques for the Bioplume-II Simulation Model of Contaminant Degradation, Master degree of Science in Engineering and Environmental Management, Air Force Institute of Technology, Air University.

Tarboush, B.J.A., Rana, D., Matsuura, T., Arafat, H.A., and Narbaitz, R.M. (2008). Preparation of thin-film-composite polyamide membranes for desalination using novel hydrophilic surface modifying macromolecules. J. Membr. Sci., 325(1), 166-175. http://dx.doi. org/10.1016/j.memsci.2008.07.037

Tu, K.L., Nghiem, L.D., and Chivas, A.R. (2010). Boron removal by reverse osmosis membranes in seawater desalination applications. Sep. Purif. Technol., 75(2), 87-101. http://dx.doi.org/10.1016/j.seppur.2010.07.021

UNEP (2012). 21 Issues for the 21st Century: Result of the UNEP Foresight Process on Emerging Environmental Issues. Nairobi, Kenya: U. N. E. P. (UNEP) http://www.unep.org/publications/ebooks/ForesightReport/.

Vrijenhoek, E.M., Hong, S., and Elimelech, M. (2001). Influence of membrane surface properties on initial rate of colloidal fouling of reverse osmosis and nanofiltration membranes. J. Membr. Sci., 188(1), 115-128. http://dx.doi.org/10.1016/S0376-788(01)00376- 3

Wang, S., and Huang, G.H. (2014). An integrated approach for water resources decision making under interactive and compound uncertainties. Omega, 44(0), 32-40. http://dx.doi.org/10.1016/j.omega. 2013.10.003

Wang, S., and Huang, G.H. (2015). A multi-level Taguchi-factorial two-stage stochastic programming approach for characterization of parameter uncertainties and their interactions: An application to water resources management. Eur. J. Oper. Res., 240(2), 572-581. http://dx.doi.org/10.1016/j.ejor.2014.07.011

Wang, S., Huang, G.H., and Veawab, A. (2013a). A sequential factorial analysis approach to characterize the effects of uncertainties for supporting air quality management. Atmos. Environ., 67(0), 304-312. http://dx.doi.org/10.1016/j.atmosenv.2012.10.066

Wang, S., Huang, G.H., Wei, J., and He, L. (2013b). Simulationbased variance components analysis for characterization of interaction effects of random factors on Trichloroethylene vapor transport in unsaturated porous media. Ind. Eng. Chem. Res., 52(25), 86028611. http://dx.doi.org/10.1021/ie4012003

World Bank. (2009). Assessment of Restrictions on Palestinian Water Sector Development: West Bank and Gaza, Washington D.C.

Zhao, Y., Hu, X.M., Jiang, B.H., and Li, L. (2014). Optimization of the operational parameters for desalination with response surface methodology during a capacitive deionization process. Desalination, 336(0), 64-71. http://dx.doi.org/10.1016/j.desal.2013.12.024

Zhu, A., Christofides, P.D., and Cohen, Y. (2009). Minimization of energy consumption for a two-pass membrane desalination: Effect of energy recovery, membrane rejection and retentate recycling. $J$. Membr. Sci., 339(1-2), 126-137. http://dx.doi.org/10.1016/j.memsci.2009.04.039

Zulkali, M.M.D., Ahmad, A.L., and Derek, C.J.C. (2005). Membrane application in proteomic studies: Preliminary studies on the effect of $\mathrm{pH}$, ionic strength and pressure on protein fractionation. Desalination, 179(1-3), 381-390. http://dx.doi.org/10.1016/j.desal.2004.11 .084 